\title{
MODEL SKEMATIK DESAIN BANGUNAN BANK SAMPAH DI DEPOK JAWA BARAT
}

Penulis Korespondensi : Ina Indah Rahmadani. Email inadirmi@gmail.com

Diterima: 28 Februari 2017

Disetujui: 31 Maret 2017

\begin{abstract}
Waste bank is an activity of non-governmental program to maintain an environment health by separating household waste into organic and non-organic category. Waste bank is managed using a system such as banking conducted by officers. For Depok city, Waste bank program have a positive impact in declining of waste volume. However, the bank's activities are currently still carried out in the activist's houses, public services house, and the path of the residential. Infact, waste bank have many potencies to support Ciliwung ecotourism planning by Depok government. This study uses Kaizen Management and Planning Method for Architectural Design. The result of this research is a schematic design model of Waste Bank building by research of society's needs for the better environment health.
\end{abstract}

Key words: eco-friendly building, energy saving, green building, waste bank model

\section{PENDAHULUAN}

DAS Ciliwung merupakan suatu DAS besar yang melintasi beberapa wilayah administratif yaitu Kota dan Kabupaten Bogor, Kota Depok hingga alirannya berakhir di wilayah Jakarta Utara menuju ke Teluk Jakarta. Panjang Sungai Ciliwung $\pm 117 \mathrm{~km}$ dan luas sekitar 347 $\mathrm{km} 2$. Berdasarkan area pengelolaannya, Sungai Ciliwung dibagi menjadi tiga bagian yaitu hulu, tengah dan hilir.

Kota Depok berada di wilayah DAS Ciliwung bagian tengah. Dari 11 kecamatan di wilayah pemerintahan Kota Depok, ada 6 kecamatan yang dilewati aliran Sungai Ciliwung yaitu Beji, Cimanggis, Limo, Pancoran Mas, Sukma Jaya, dan Cilodong. Aliran sungai Ciliwung di wilayah Depok melewati area permukiman padat, perumahan, perkebunan hingga area industri, menyebabkan Sungai Ciliwung rentan pencemaran.

Seiring dengan meningkatnya kepedulian masyarakat pada kebersihan Sungai Ciliwung, pemerintah Kota Depok berencana untuk menjadikan Sungai Ciliwung sebagai salah satu destinasi ekowisata. Kondisi air Sungai Ciliwung di wilayah Depok lebih baik dibandingkan di bagian hilir sehingga masih banyak jenis ikan yang dapat hidup. Gradien sungai juga tidak terjal sebagaimana yang dijumpai di hulu. Situasi ini merupakan potensi untuk dapat mengembangkan ekowisata sungai

Untuk mewujudkan rencana Sungai Ciliwung menjadi salah satu destinasi ekowisata, maka kebersihan lingkungan sungai dan sekitarnya harus terus terjaga. Sungai dan wilayah bantarannya harus bebas sampah. Salah satu upaya membebaskan Sungai Ciliwung dari sampah yaitu dengan 
mengajak masyarakat meningkatkan peran Bank Sampah. Manfaat Bank Sampah selain mendorong lingkungan semakin bersih, mendidik masyarakat lebih bijak memperlakukan sampah, juga dapat menambah pendapatan keluarga. Sampahsampah kering domestik seperti kaleng, kardus, pecahan kaca, dan sampahsampah yang masih bernilai ekonomis dikum-pulkan untuk dijual ke pengepul sedangkan sampah basah seperti sisa makanan dikumpulkan dan diolah di UPS untuk menjadi kompos.

Bank Sampah Kencana 48 yang berlokasi di wilayah studi telah berhasil mendorong terciptanya lingkungan bersih dan hijau. Nasabah Bank Sampah semakin bertambah. Tidak hanya para ibu rumah tangga, anak-anak pun sudah mulai tertarik dengan kegiatan menabung sampah ini. Satu hari dalam seminggu, Bank Sampah menjalankan kegiatannya. Pengurus Bank Sampah kebanyakan adalah local heroes yang bekerja dengan sukarela demi kemajuan daerah mereka. Namun hingga saat studi dilakukan, kegiatan Bank Sampah masih dilaksanakan secara berpindah-pindah antara lain di posyandu, menumpang di rumah pengurus Bank Sampah, bahkan di jalan-jalan lingkungan tempat tinggal. Akibatnya, kegiatan Bank Sampah masih pada tahap mengumpulkan dan menjual sampah saja.

Bank Sampah berpotensi untuk mendukung agenda kegiatan ekowisata yang dicanangkan oleh Pemerintah Kota Depok karena keberadaannya membawa perubahan positif bagi lingkungan secara fisik mupun sosial. Oleh karena itu sudah selayaknya jika Bank Sampah diberikan ruang tersendiri. Tidak hanya sebagai tempat mengumpulkan dan menjual sampah saja tetapi dapat digunakan pula sebagai tempat bersosialisasi, memotivasi, mengedukasi, berinovasi dan galeri kerajinan berbahan dasar sampah.

Penelitian ini bertujuan untuk menyusun skematik desain prototipe bangunan Bank Sampah yang mewadahi aktifitas di dalamnya. Bangunan akkan menggunakan konsep ramah lingkungan dan hemat energi dalam usaha menata lingkungan di wilayah garis sempadan Sungai Ciliwung bagian tengah.

\section{METODOLOGI}

Penelitian berlangsung pada bulan April hingga September Tahun 2016. Secara holistik, bersifat kualitatif dengan pendekatan rasionalistik tentang kebersihan dan keindahan alami di sekitar lingkungan Sungai Ciliwung.

Penentuan lokasi berdasarkan pertimbangan pada keberlanjutan pengelolaan Bank Sampah yang sudah beroperasi paling sedikit 1 tahun. Secara administratif lokasi berada di wilayah RW 08 Kelurahan Kalimulya Kecamatan Cilodong, Kota Depok, Jawa Barat, Indonesia (Gambar 1). Luas Kelurahan Kalimulya 223.058 ha. Sebelah barat berbatasan langsung dengan Sungai Ciliwung.

Pengumpulan data dilakukan dengan

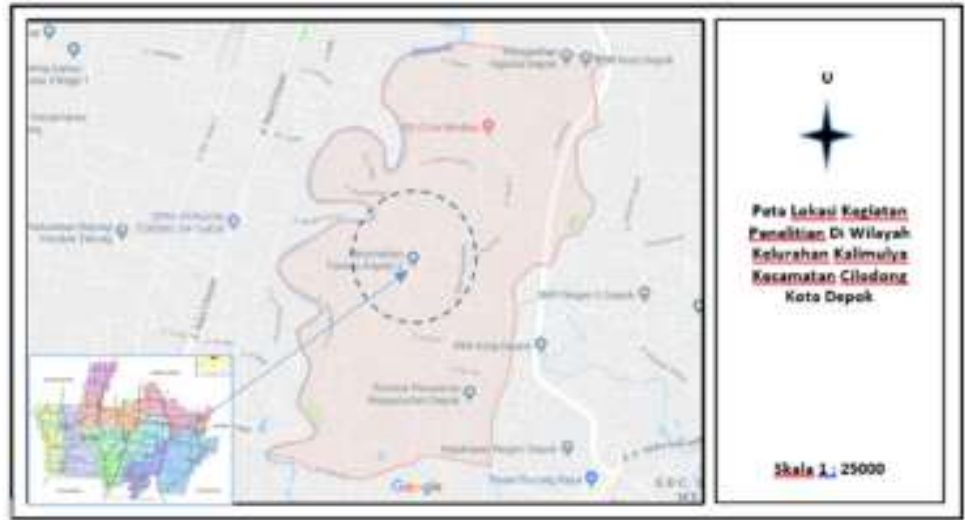

Gambar 1. Lokasi penelitian 
studi literatur, survey lapang, melakukan wawancara, memberikan kuesioner, dan melakukan tes laboratorium untuk menguji kualitas air Sungai Ciliwung yang melewati lokasi.

Manajemen Kaizen digunakan untuk menganalisa fenomena yang melibatkan banyak orang. Langkah-langkah dalam Kaizen adalah (1) seleksi Tema; (2) membuat diagram sebab-akibat dan analisis situasi; (3) menganalisis lembar periksa; (4) menetapkan sasaran; (5) langkah dan pelaksanaan; dan (6) Mengesahkan hasilnya.

Hasil analisis Kaizen selanjutnya diintegrasikan dengan Metode Perencanaan dan Perancangan Arsitektur sebagai bidang utama pemecahan masalah dalam keilmuan arsitektur. Pada tahap ini, dilakukan penyusunan konsep ruang dan pengujian gambar kerja bangunan Bank Sampah oleh pakar bangunan di lingkungan Universitas Jayabaya.

\section{HASIL DAN PEMBAHASAN}

Bank Sampah Kencana 48 merupakan "embrio" untuk mendukung agenda Pemerintah Kota Depok mewujudkan Kali Ciliwung sebagai destinasi ekowisata perkotaan. Kegiatan Bank Sampah ini adalah mendidik warga kategori yaitu sampah basah dan kering. Sampah basah seperti sisa makanan ditiriskan. Lalu setiap 2 hari akan dibawa oleh petugas pengumpul untuk dibawa ke UPS dan diolah menjadi pupuk kompos dengan system fermentasi.

Sampah kering dipisahkan berdasarkan materialnya antara lain kaleng, plastik, styrofoam, kertas. Sampah tersebut dibawa nasabah ke Bank Sampah dan ditimbang beratnya. Hasil penimbangan berat sampah dikalikan dengan harga dasar sampah (Rp).

Misalnya, nilai satu buah botol kecap bekas dan tidak pecah adalah $\mathrm{Rp}$ 500/buah dan nilai satu kilogram besi tebal atau stainless steel adalah $\mathrm{Rp}$ $1.700 / \mathrm{kg}$. Maka petugas akan mencatat berapa botol yang dibawa nasabah dikalikan nilai botol/buah dan berapa kilogram stainless steel yang dibawa nasabah dikalikan nilai per kilogram. Selanjutnya harga-harga dari sampah itu dicatat pada buku nasabah Bank Sampah. Kegiatan Bank Sampah Kencana 48 terlihat pada Gambar 2 dan skema pengelolaan sampah di RW 08 Kelurahan Kalimulya dapat dilihat pada Gambar 3.

Situasi berimplikasi pada perilaku membuang sampah pada tempat yang telah ditentukan dan kesadaran akan manfaat sampah yang masih dapat di daur
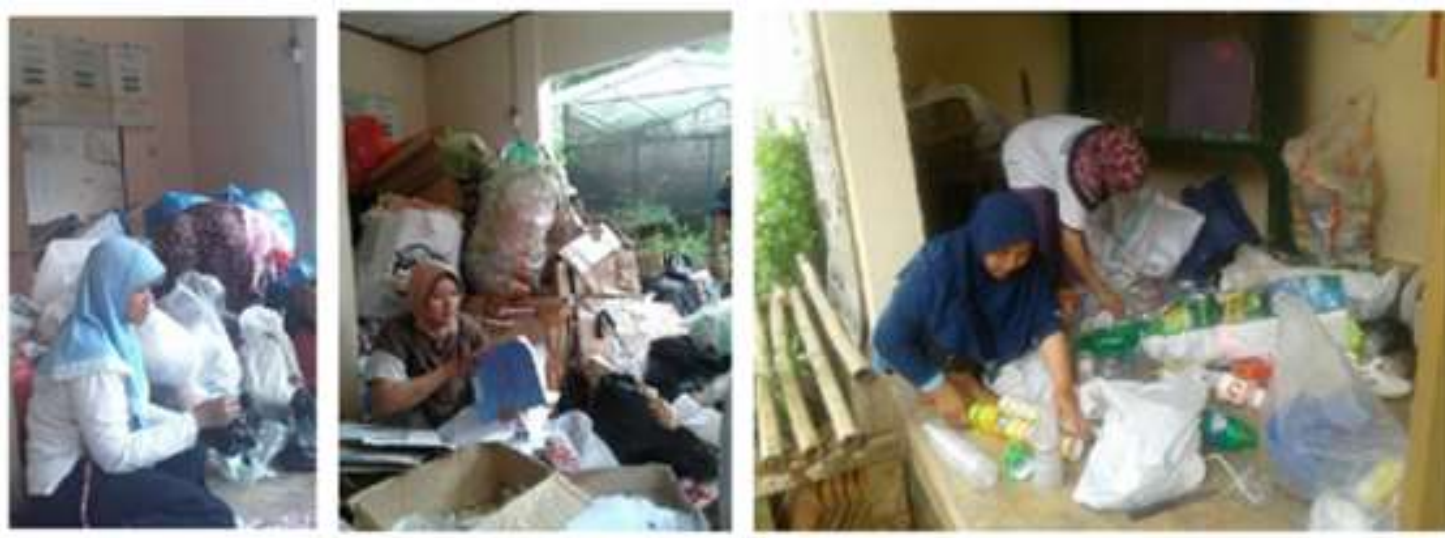

Gambar 2. Kegiatan bank sampah Kencana 48

memilah dan memilih sampah rumahtangga. Sampah dibagi menjadi dua ulang. Untuk lebih jelasnya dapat dicermati pada Fishbone Diagram Sebab 


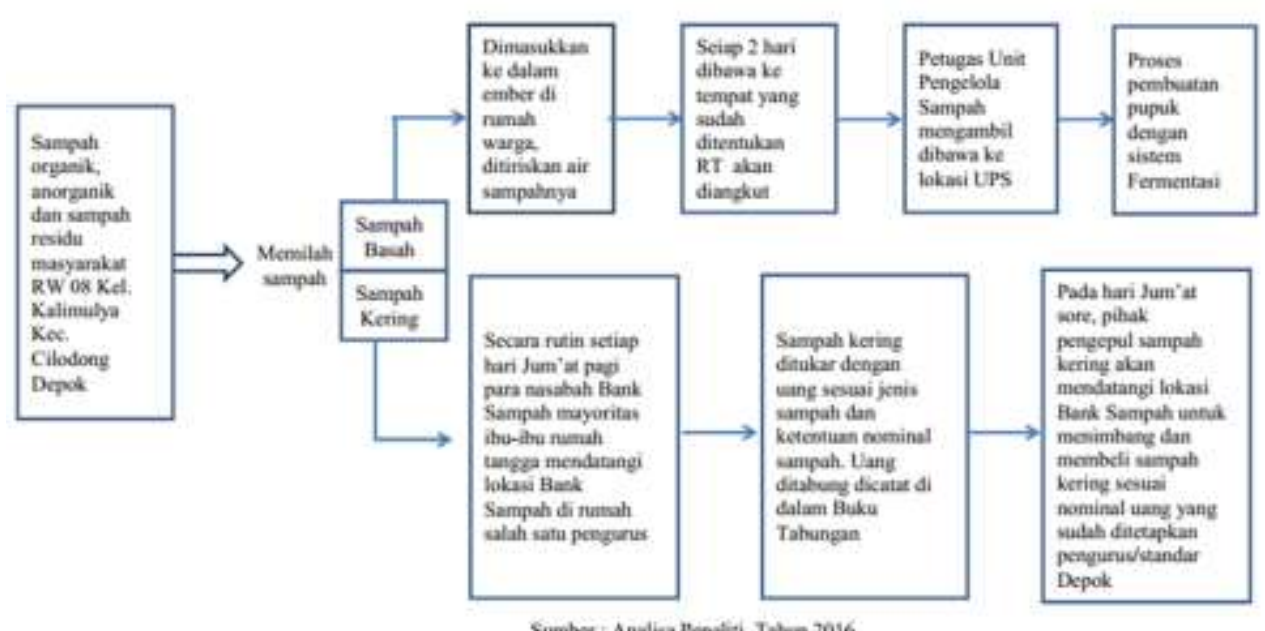

Gambar 3. Skema pengelolaan sampah

Akibat dan Analisis Situasi (fishbone) dalam Gambar 4.

Analisa lembar periksa menunjukkan bahwa responden telah memahami jenis kegiatan dan manfaat bank sampah. Manfaat bank sampah bagi lingkungan dan masyarakat menurut responden yaitu: (1) meningkatkan kesadaran masyarakat akan pentingnya banjir akibat penumpukan sampah di sungai; (6) menghasilkan uang dan membantu perekonomian keluarga.

Harapan responden bank sampah di wilayah studi yaitu (1) dapat menjadi solusi terhadap masalah lingkungan; (2) bank sampah memiliki bangunan tersendiri; (3) dan dapat menjadi wadah silaturahmi antar warga.

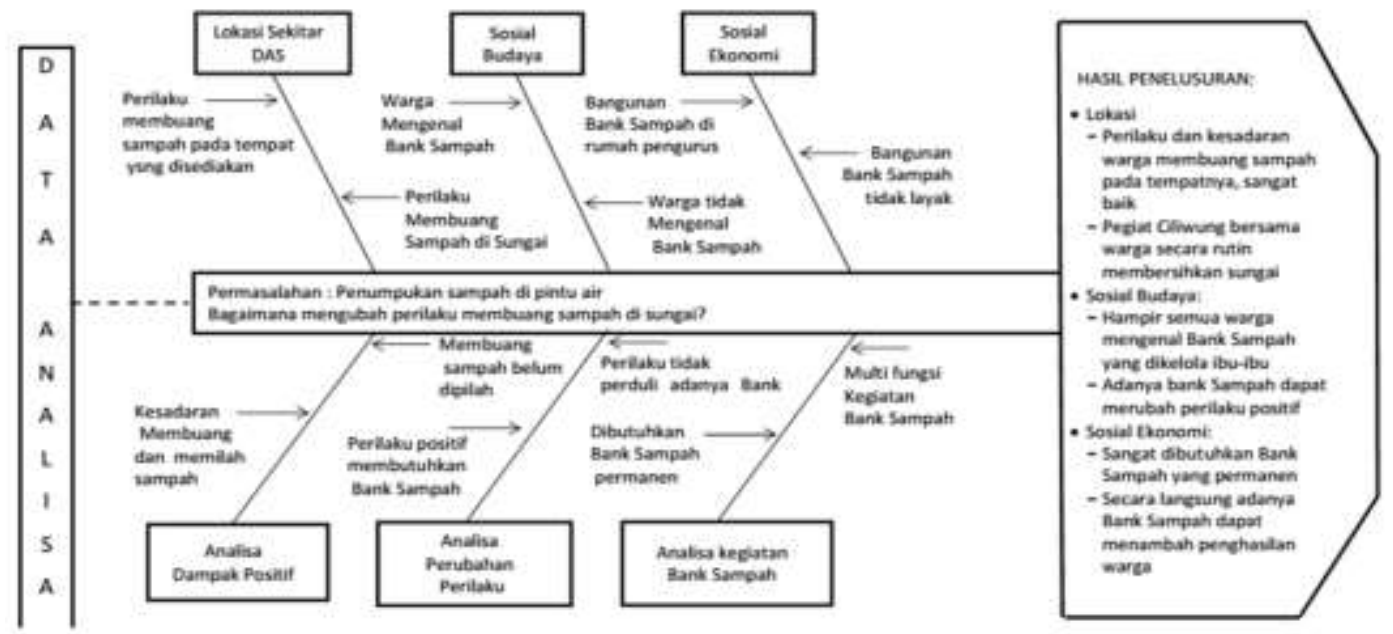

Gambar 4. Diagram sebab akibat dan analisis situasi kebutuhan bangunan bank sampah

kebersihan lingkungan; (2) menciptakan lingkungan menjadi lebih bersih dan hijau; (3) mengurangi pencemaran lingkungan; (4) mengurangi penumpukan sampah di TPS; (5) mencegah bencana
Responden juga memberikan pendapat mengenai ruang yang ada pada rencana bangunan Bank Sampah yaitu: (1) bank sampah diharapkan tidak hanya menjadi tempat memilah, mengumpul dan 
Tabel 1. Program Ruang Bank Sampah

\begin{tabular}{clccc}
\hline $\begin{array}{c}\text { Lantai } \\
\text { Bangunan }\end{array}$ & \multicolumn{1}{c}{ Kebutuhan Ruang } & $\begin{array}{c}\text { Jumlah } \\
\text { Unit }\end{array}$ & $\begin{array}{c}\text { Luas Ruang } \\
\left(\mathrm{m}^{2}\right)\end{array}$ & $\begin{array}{c}\text { Jumlah } \\
\text { Luasan }\left(\mathrm{m}^{2}\right)\end{array}$ \\
\hline 1 & R. Pencatatan dan Penimbangan & 1 & 42,50 & 42,50 \\
& R. Pengelola Bank Sampah & 1 & 8,00 & 8,00 \\
& Toilet & 1 & 4,00 & 4,00 \\
& Pantry & 1 & 4,00 & 4,00 \\
& Tangga & 1 & 5,50 & 5,50 \\
\hline \multicolumn{2}{c}{ Total Lantai 1 } \\
\hline \multirow{2}{*}{ R. Pelatihan } & 1 & 16,99 & 64,00 \\
& R. Kantor Pendampingan & 1 & 5,50 & 16,99 \\
& Toilet & 1 & 4,00 & 4,00 \\
& Pantry & 1 & 4,00 & 4,00 \\
& Tangga & 1 & 5,50 & 5,50 \\
& Koridor & 1 & 29,00 & 29,00 \\
\hline \multicolumn{4}{c}{ Total Lantai 2 } \\
\hline
\end{tabular}

mencatat tetapi juga sebagai tempat mengolah sampah menjadi barang bernilai ekonomis; (2) bangunan menyediakan ruang pameran hasil-hasil kerajinan dari sampah; (3) bangunan itu dapat pula digunakan menjadi ruang serbaguna bagi warga.

Pemilihan lokasi berdasarkan pada kriteria yaitu : (1) lokasi mudah di akses dari lingkungan perkampungan dan kompleks perumahan Taman Anyelir; (2) lokasi memang diperuntukkan sebagai fasilitas umum. Dari dua lokasi yang ada, lokasi terpilih adalah fasum di Perumahan Anyelir yang berada di dekat perkampungan.

\section{Model Perencanaan dan Perancangan Bangunan Bank Sampah}

Penyusunan skematik disain diawali dengan mengidentifikasi kebutuhan ruang berdasarkan kegiatan-kegiatan yang direncanakan berdasarkan data masukan dari kegiatan Focus Group Discussion (FGD); menyusun program ruang dan organisasi ruang. Selanjutnya dibuat gambar skematik bangunan bank sampah berupa denah - tampak - potongan. Saran dan masukan didapatkan dari kegiatan Uji
Disain untuk melengkapi gambar Detail Engineering Design supaya gambar lebih akurat.

Kajian aspek kegiatan dan pengguna memunculkan program ruang yang dapat dilihat pada Tabel 1. Selanjutnya disusun struktur organisasi ruang berdasarkan hirarki dalam Gambar 5.

\section{Konsep Fasade (tampak depan) \\ BangunanBangunan Bank Sampah} terinspirasi dengan slogan daur ulang $5 \mathrm{R}$ yaitu: reduce (mengurangi sampah); reuse (mengguna-kan kembali); recycle (mendaur ulang sampah organik); replace (menghindari barang sekali pakai); repair (memperbaiki barang rusak agar dapat diperbaiki kembali).

Bentuk bangunan mengambil filosofi dari simbolisasi segitiga emas yaitu berupa cawan, cerobong dan intan. Cawan dianalogikan sebagai tempat menampung, cerobong dimaknai sebagai proses daur ulang dan intan melambangkan barang berharga. Makna secara luas adalah sampah jika sampah dikelola dengan baik tidak hanya akan mampu menghasilkan profit tetapi juga benefit bagi warga dan lingkungan. 
Lantai 1

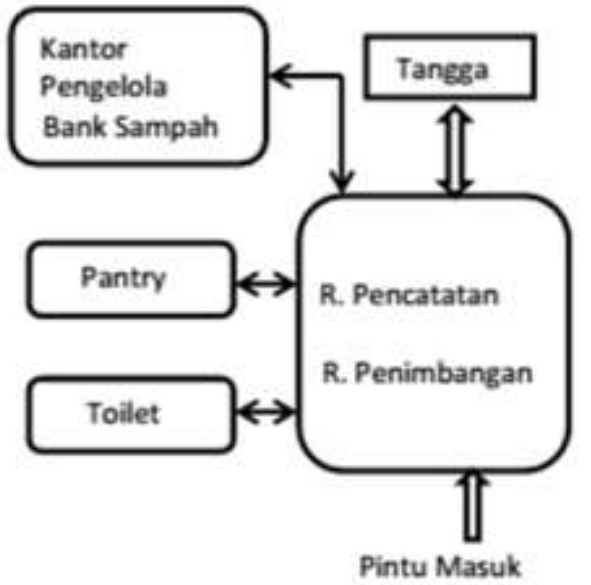

Lantai 2

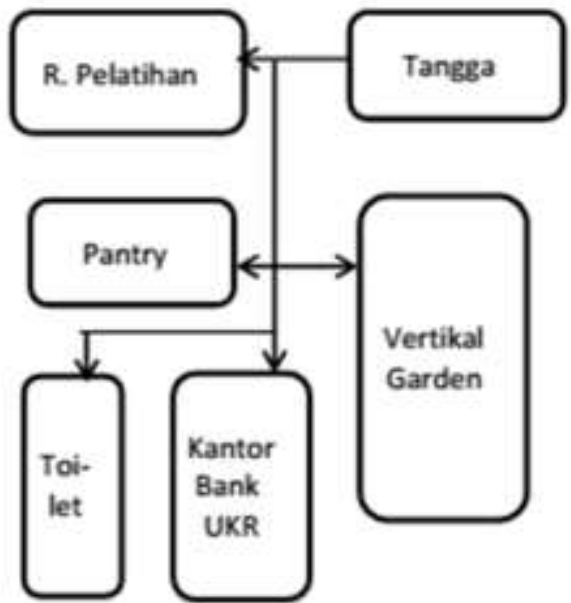

Gambar 5. Struktur Organisasi Ruang Bangunan Bank Sampah

Tujuan filosofi ini ialah merubah mindset warga terhadap sampah. Pemikiran membuang sampah berganti menjadi pemikiran untuk memilih dan memilah sampah. Perilaku membuang berubah menjadi perilaku menabung. Bank sampah akan meningkatkan kebersihan lingkungan dan kesejahateraan warga.

Berdasarkan program ruang dan struktur organisasi ruang yang ada maka denah, tampak bangunan dan gambar potongan/struktur di disain sebagaimana pada Gambar 6, Gambar 7 dan Gambar 8.
Model bangunan Bank Sampah ini menggunakan pendekatan "Hemat Enegi dan Ramah Lingkungan", yaitu suatu pendekatan yang dapat digunakan pada penataan ruang-ruang dalam bangunan untuk mendapatkan aspek-aspek positif yang sebesar-besarnya dan menghindarkan aspek yang merugikan. Pendekatan ini bisa dicapai antara lain dengan pemilihan material yang akan digunakan.

Bangunan Bank Sampah ini antara lain akan menggunakan material bata lubang angin (roster) yang berguna untuk

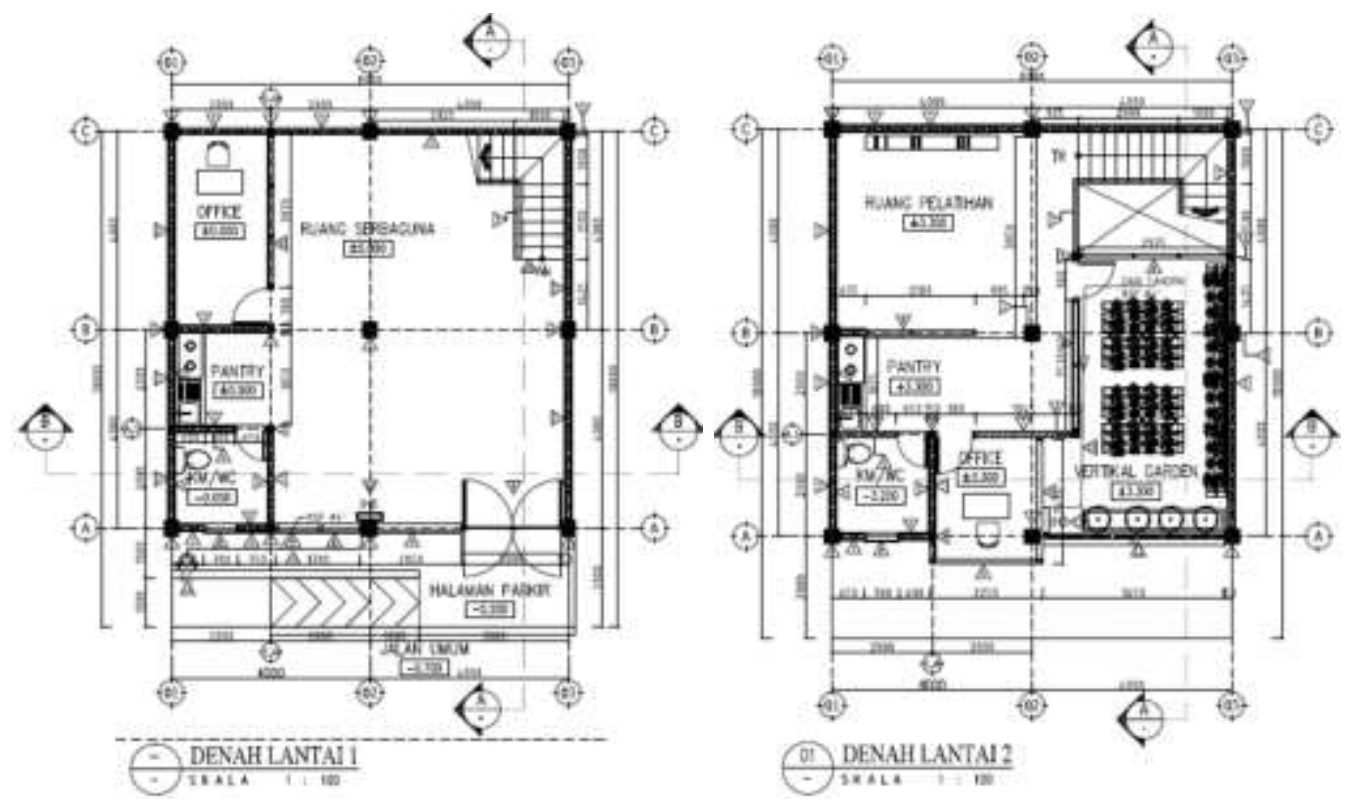

Gambar 6. Denah Bangunan Lantai 1 dan 2 

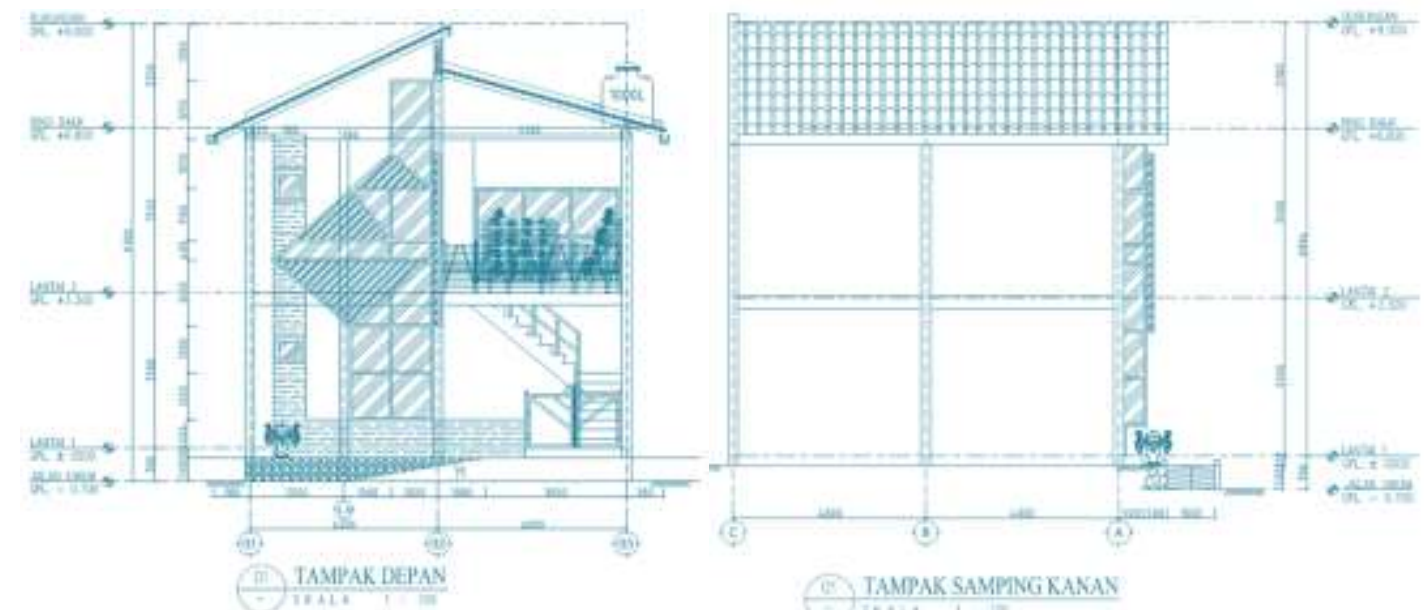

Gambar 7. Tampak Depan dan Samping Kanan Bangunan
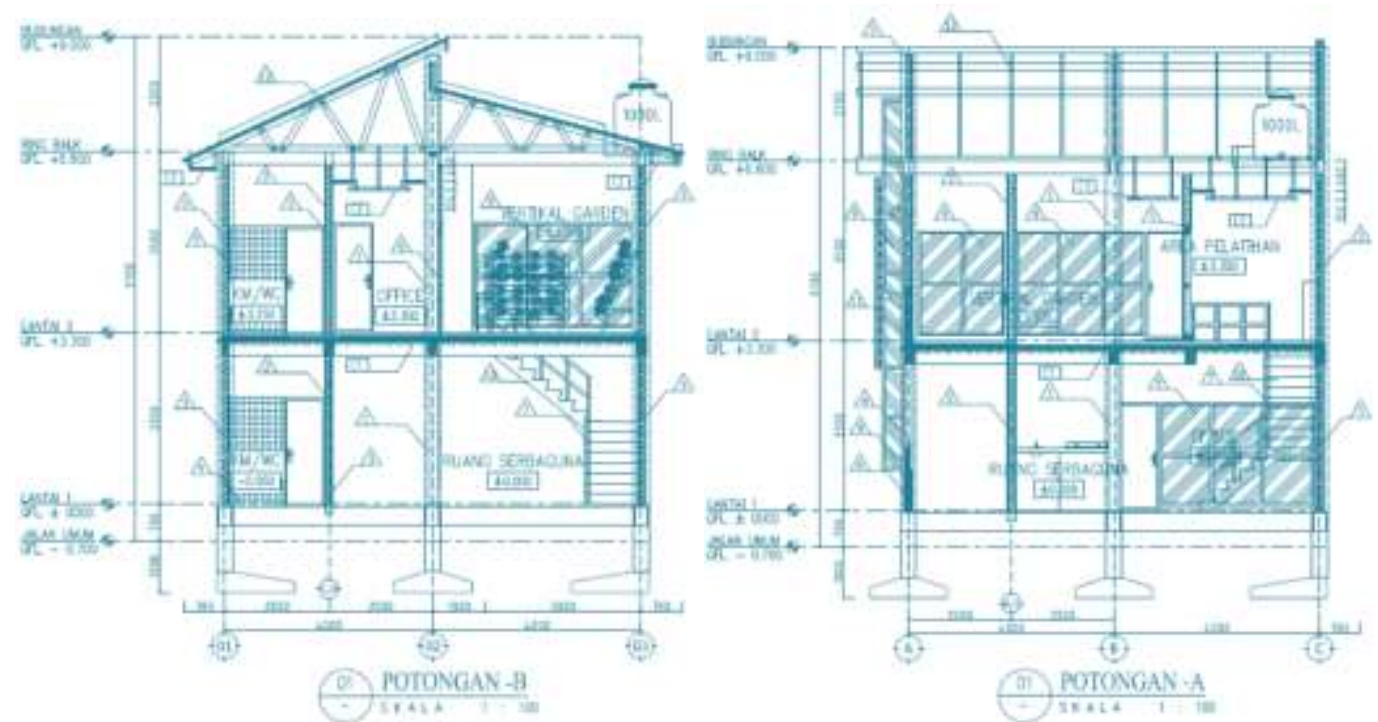

Gambar 8. Potongan A-A dan B-B

sirkulasi udara. Penempatan elemen pintu, jendela, dan lubang angin-angin dengan pilihan model yang mampu mengalirkan udara sesuai keperluan bangunan Bank Sampah.

Material transparan bening untuk membiarkan cahaya masih bisa masuk ke dalam ruangan agar mengurangi pemakkaian lampu pada siang hari. Material transparan buram guna menghindari terpapar sinar matahari secara langsung. Konsep bangunan hijau pada bangunan Bank Sampah juga terlihat pada penempatan taman vertikal di bagian depan lantai 2 disajikan pada Gambar 9.

\section{KESIMPULAN}

Penelitian ini menghasilkan prototype bangunan Bank Sampah berdasarkan identifikasi kegiatan dari para pengguna. Bangunan terdiri atas 2 lantai. Lantai 1 akan mewadahi Ruang Pencatatan dan Penimbangan, Ruang Pengelola Bank Sampah, Toilet, Pantry dan tangga. Sedangkan lantai 2 akan mewadahi kegiatan pelatihan, Ruang kantor pendampingan, Toilet, Pantry, Tangga dan Koridor. Bangunan menggunakan pendekatan "Hemat Enegi dan Ramah Lingkungan" yang dicapai dengan pemilihan material bangunan. 
Material kaca untuk membiarkan cahaya masuk, material berlubang untuk membiarkan udara tetap dapat tersirkulasi dengan baik. Dengan demikian, keberadaan bangunan ini akan sejalan dengan upaya penataan lingkungan.

Bangunan Bank Sampah didisain berdasarkan suatu filosofi dengan tujuan merubah mindset terhadap sampah dan mengubah dan perilaku membuang
Hibah Bersaing Tahun 2016; Pemerintah Kota Depok; Bpk Taufik Des serta para penggiat lingkungan atas kecintaan dan bakti mereka yang sangat besar terhadap kelestarian Sungai Ciliwung; Warga RW 08 Kelurahan Kalimulya Kecamatan Cilodong; dan semua pihak yang telah membantu kelancaran studi ini.

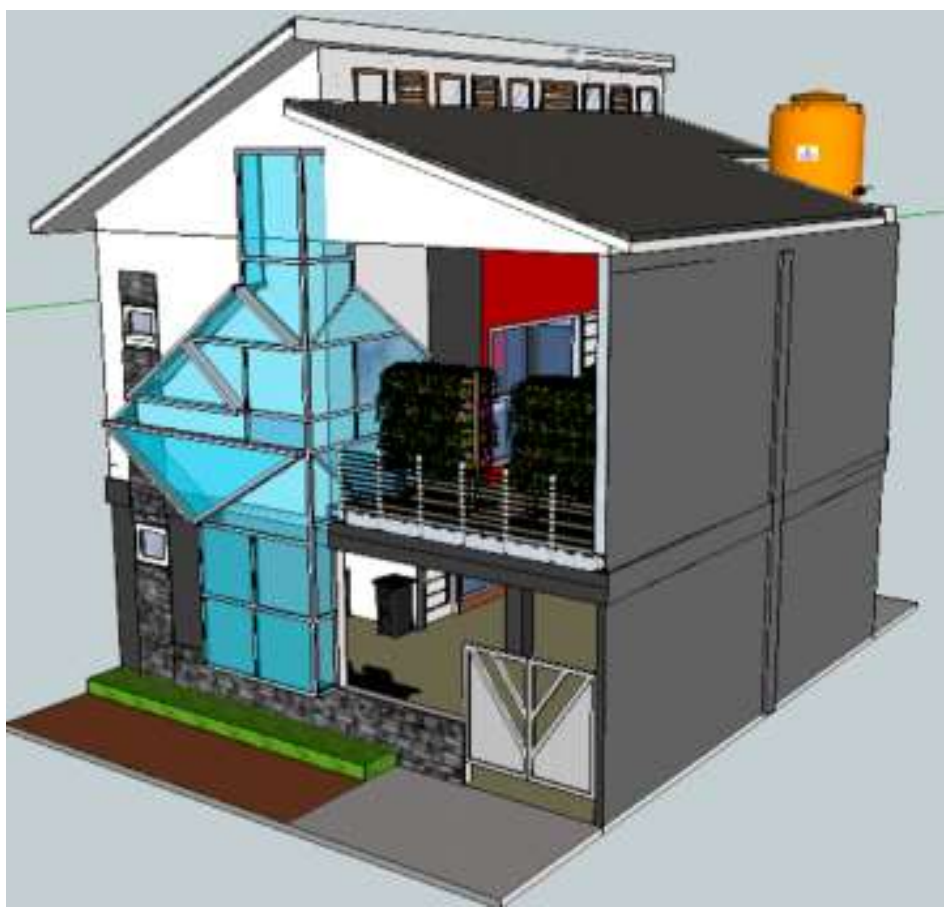

Gambar 9. Konsep Bangunan Hijau (Green Building)

menjadi perilaku menabung. Sampah yang dikelola dengan baik didukung oleh suatu bangunan yang layak dapat membuat masyarakat hidup di lingkungan yang bersih, sejahtera dan berkecukupan. Kebersihan lingkungan Sungai Ciliwung pada akhirnya akan mensukseskan rencana pemerintah untuk menjadikan Kota Depok sebagai destinasi baru ekowisata di perkotaan.

\section{UCAPAN TERIMAKASIH}

Terimakasih dan penghargaan sebesar-besarnya kami sampaikan kepada Kemenristek Dikti sebagai penyelenggara

\section{DAFTAR PUSTAKA}

Anonim. 2007. Peraturan Menteri Pekerjaan Umum Nomor 06/PRT/ M/2007 Tanggal 16 Maret 2007 Tentang Pedoman Umum Rencana Tata Bangunan dan Lingkungan.

Anonim, 2016. Badan Pusat Statistik Daerah Kecamatan Cilodong 2015.

Ceballos-Lascurain, H. 1996. Tourism, Ecotourism and Protected Areas. The State of Nature-based Tourism around the World and Guidelines for its Development. IUCN (International Union for the Conservation of Nature), 
Gland, Switzerland and Cambridge, UK.

Ching, Francis DK. 2007. Arsitektur Bentuk, Ruang, dan Tatanan. John Wiley \&Sons, Inc Allright Reserved. Edisi Ketiga. Penerbit Erlangga. Jakarta

Groat, Linda N. and Wang, David. 2013. Architectural Research methods. Printed in the United States of America.

Karyono, Tri Harso. Green Arsitektur. Pengantar Pemahaman Arsitektur Hijau di Indonesia. Rajawali Pers. PT. Raja Grafindo Persada.

Kurniasari, Eva. 2010. Strategi Pengembangan Ekowisata Melalui Peningkatan Partisipasi Masyarakat Studi Kasus Komunitas Kelurahan Kalimulya Kota Depok. SPS Institut Pertanian Bogor. Bogor

Laksito, Boedhi. 2014. Metode Perencanaan dan Perancangan Arsitektur. Griya Kreasi (Penebar Swadaya Grup). Jakarta.

Marfai, Muh.Aris. 2012. Pengantar Etika Lingkungan dan Kearifan Lokal. Gajahmada University Press. Yogyakarta.

Mediastika, Christina E. 2013. Hemat Energi dan Lestari Lingkungan Melalui Bangunan. Penerbit Andi. Yogya-karta

Snyder J.C \& Catanese AJ. 1997. Pengantar Arsitektur. McGraw-Hill, Inc. Cetakan Keempat. Penerbit Erlangga. Jakarta. 
JSIL | Endang Wahyuningtyas dkk. : Model Skematik Desain Bangunan Bank Sampah 